Proc. Indian Acad. Sci. (Earth Planet. Sci.), Vol. 98, No. 1, April 1989, pp. 125-132.

(C) Printed in India.

\title{
The importance of strong motion seismology in India
}

\author{
BRUCE A BOLT and JAMES N BRUNE* \\ Departments of Geology and Geophysics and Civil Engineering, University of California, \\ Berkeley, California 94720, USA \\ * Seismological Laboratory, Department of Geological Sciences, Mackay School of Mines, \\ University of Reno, Reno, Nevada 89557, USA
}

\begin{abstract}
The high seismicity of portions of the Indian peninsula, together with the high density of population and industrial growth, results in a significant seismic risk in many parts of the subcontinent. Large construction projects throughout the peninsula require an adequate basis for earthquake-resistant design. Thus, as well as strong scientific arguments, there are major practical reasons why a substantial programme to record strong seismic ground motion should be carried out in India. This paper first reviews the history of strong motion instrumental recording, beginning with the important accelerograms obtained in the Koyna earthquake of 11 December 1969 through the recent increase in strong motion instrumentation, particularly in association with construction of large dams. It is argued that there is a pressing need for further extension of strong motion accelerograph coverage of India, especially along the seismically active regional thrust faults of the Himalayan region. Such programme expansion should follow deliberate strategies of site selection, designed to optimize the scientific and practical returns, given the requirements of minimum costs, reliable maintenance and accessible data.
\end{abstract}

Keywords. Seismicity; strong motion seismology; strong motion instrumentation; ground motion recording.

\section{Introduction}

There are three main reasons why a programme aimed at obtaining widespread recordings of strong earthquakes in India is necessary. First, the large and growing population and rapid construction of major engineered structures demand mitigation of the high earthquake risk; secondly, such earthquake measurements contribute to the basic understanding of the complex tectonics of northern India; and thirdly, the unique continent-continent collision plate boundary of the Himalayas provides a valuable opportunity to further understanding of earthquake source physics and the generation of strong ground motion by thrust faults.

The first two of these propositions have been discussed by Krishna (1981) who pointed out that because Peninsular India contains some of the most seismically active areas of the world there are both broad scientific and important social reasons for adequate measurements of strong ground motions. As illustrated in figure 1, India has had many strong earthquakes since the last century, six of them having a magnitude greater than 8 , and 55 with a magnitude between 6.5 and 8.0. Most but not all of these damaging earthquakes have been from strain release in the Himalaya region, extending from Assam in the east to Kashmir in the north, with most of the seismic energy taking place in northeast India. Overall there has been a considerable amount of shaking damage, particularly to poorly-designed buildings, as well as other serious consequences due to liquified soil, subsidence, landslides and failure of 


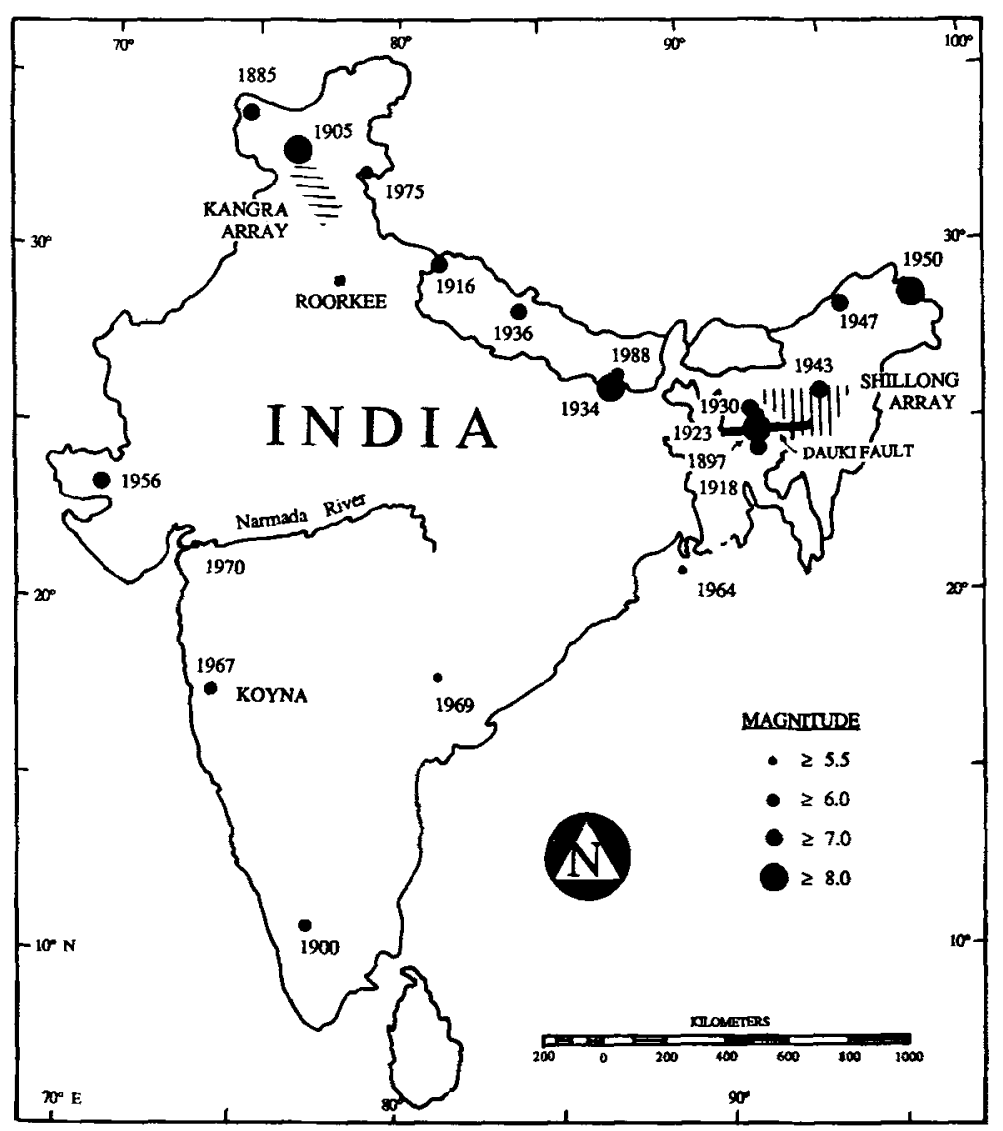

Figure 1. Plot of some historical India earthquakes (adopted from Kaila and Sarkar 1978).

bridges through unequal soil settlement. Because of population and construction increase, the next major earthquake could have even greater damage and loss of life than any previous Indian earthquake. Yet, due to a lack of instrumental observations of strong ground motion in India to date, no suitable attenuation laws for large amplitude seismic waves are available (Khattri et al 1983) and no reliable estimates for local site effects.

There are already available comprehensive earthquake catalogs (Bapat et al 1983) and maps of earthquake epicenters (Rao and Rao 1984) as well as seismic intensity zoning maps and seismic risk maps of India (Kaila and Sarkar 1978; Kaila and Rao 1979). Some studies of major fault and seismicity patterns and relevant recent tectonics have also been published (e.g. Chandra 1977; Molnar and Pandey, Ni, Khattri et al all in this volume). This material provides a sound basis for planning an extended strong motion instrument network with accompanying priorities and probabilities of observational success.

\section{Seismicity}

Earthquakes occur in many parts of India with very variable recurrent rates (Rao and 
Rao 1984; Gupta et al 1986). Along the Himalayan thrust belt and surrounding areas they are felt almost daily. The high seismicity is exemplified by the twenty earthquakes with magnitudes greater than 5.8 and ten with magnitudes greater than 6.5 that occurred along the southern and eastern boundary of the Shillong Plateau, east of Dauki and north and northeast of Halflong during the last 70 years.

The Dauki-Halflong fault zone (see figure 1), along the straight east-west portion of the Assam-Bangladesh border, has shown medium local seismicity in the last 70 years, forming a seismic gap between adjacent regions with larger recent earthquakes. In terms of the usual frequency-magnitude relation, this fault zone gives an $a$ value of 3.8 (40-year period value) and a $b$ value of $0 \cdot 45$. The low $b$-value suggests the existence of high shear stress in the region.

In the meizoseismal area of the Great Assam earthquake of 1897, the probability in 10 years for ground accelerations greater than $0.2(M>6.5)$ is very high with an estimated value of about $0 \cdot 8$. For this reason, a strong motion earthquake array was proposed for this area at the International Workshop on Strong Motion Earthquake Instrument Arrays held in Honolulu, Hawaii in 1978 (Iwan 1978).

To the south, India is also subject to damaging earthquakes in some regions (see figure 1). The earlier view that most of the Peninsula is aseismic has had to be revised. India differs in this respect from most other large shield areas which have low seismic risk. Examples of recent damaging earthquakes are Koyna (10 December 1967), Bhadrachalam (13 April 1969), Broach (23 March 1970), Hyderabad (30 June 1983) and Dharamsala (26 April, 1986). One estimate of the $b$-value for Peninsula India is $b=0.85$ (with $a=4 \cdot 4$ ), which is typical of moderate seismic region (Rao and Rao 1984). Historical earthquakes in the peninsula are concentrated (1) to the northwest from about Koyna through Surat to Kutch; (2) to the eastern coastal zone from about Madras to Nagaran, and (3) in the southernmost region from about Travancore to Bangalore.

\section{Present strong motion instrument network}

One of the motivations for strong motion recorders in India was the construction of large dams in India (Rau and Varma 1981). The first strong motion instruments of modern type were installed as early as 1963 at Koyna Dam in Maharashtra. Small earthquakes were located after the reservoir started filling in 1962. This part of India had been considered to be nearly non-seismic, and the occurrence of the damaging earthquake (magnitude 7) near Koyna Dam in 1967 was a surprise (Tandon and Choudhury 1968; Chopra and Chakrabarti 1973).

This experience stimulated various plans for an India National Network consisting of about 100 strong motion accelerographs to be placed in appropriate sites to cover the entire country. The concept included a supplementation of locally built accelerometers called RESA by 500 simplified instruments (termed SSR and similar in design to the U.S.G.S. seismoscope). As of August 1983, 20 RESAs and 200 SSRs had been installed in the field. These instruments were designed, fabricated and maintained by the Department of Earthquake Engineering at the University of Roorkee.

In addition, several river valley project sites in India have installed strong motion instrumentation both in the free field and at various elevations in the engineered 
structures. These instruments are of different manufacturing types, and include the AR240, RS250, SMA1 designs, as well as the RESA. Dams at sites distributed around India that have strong motion recorders in the body of the dam include Beas, Bhakra, Ramganga, Yamuna, Ukai, Kadana, Koyna and Iddiki (Rau and Varma 1981). In 1987, about 28 such accelerographs were reported operational at various dams (Chandrasekaran 1987).

In response to the 1978 recommendation from the Hawaii International Workshop, a joint Indian-U.S. project of 50 strong motion instrument stations, originally recommended as a large-scale strong motion array in the Assam region, was established in the Kangra region of the state of Himachal Pradesh (see figure 1). In 1906, this area experienced an $8+$ magnitude earthquake. Forty-six accelerometers were installed by August 1983. The Kangra array is roughly in the form of a rectangular grid, with principal north-west to south-east axis, spanning $1.5^{\circ}$ in latitude and $2^{\circ}$ in longitude. The array covers the main fault trends in this region. The elevation varies between 500 and 2500 meters.

Somewhat later, a strong motion network at 45 sites called the Shillong strong motion array (see figure 1) began to be installed in Assam, also under the auspices of the University of Roorkee. This array covered the area between $25^{\circ} \mathrm{N}$ to $26^{\circ} \mathrm{N}$ latitude and $91^{\circ} \mathrm{E}$ to $93.5^{\circ} \mathrm{E}$ with station spacing about $30 \mathrm{~km}$. This rather remote region presents considerable logistic difficulties in access and services. The installation and maintenance of the Shillong array reflects much credit and dedication on the sponsoring organizations.

Other groups in India are also active with research based on strong motion recording. For example, at the National Geophysical Research Institute at Hyderabad, digital accelerometers have been deployed in seismically active areas and appropriate digital data processing algorithms are being developed.

Parenthetically, we mention that the planned high-level bridge across the Jamuna (Brahmaputra) River in Bangladesh is being designed incorporating seismic resistance against substantial earthquakes. It is anticipated that part of the World Bank-funded project will be the installation of strong motion instruments in the East Bengal region.

\section{Recordings of ground motion}

Up to 1986 , the only strong ground motions recorded by Indian accelerographs were those near the Koyna Dam $230 \mathrm{~km}$ southeast of Bombay on the Pre-Cambrian Shield, and no time histories of Himalayan earthquakes were available, although seismoscope records had been obtained for about 5 events in that region. The accelerograms recorded in the Koyna earthquake on December 11, 1967, with the peak horizontal acceleration of $0.63 \mathrm{~g}$, represented an important class of recorded ground motions. These accelerations were the highest directly measured in the world up to that time.

The persistent interest of Indian earthquake engineers and seismologists began to bear fruit in 1986 with clear analog recordings of strong ground acceleration in earthquakes in the northern seismic region by a number of stations of the Kangra array. Figure 2 reproduces an accelerogram and velocity and displacement ground motions recorded in the Himachal Pradesh earthquake, April 26, 1986. The 

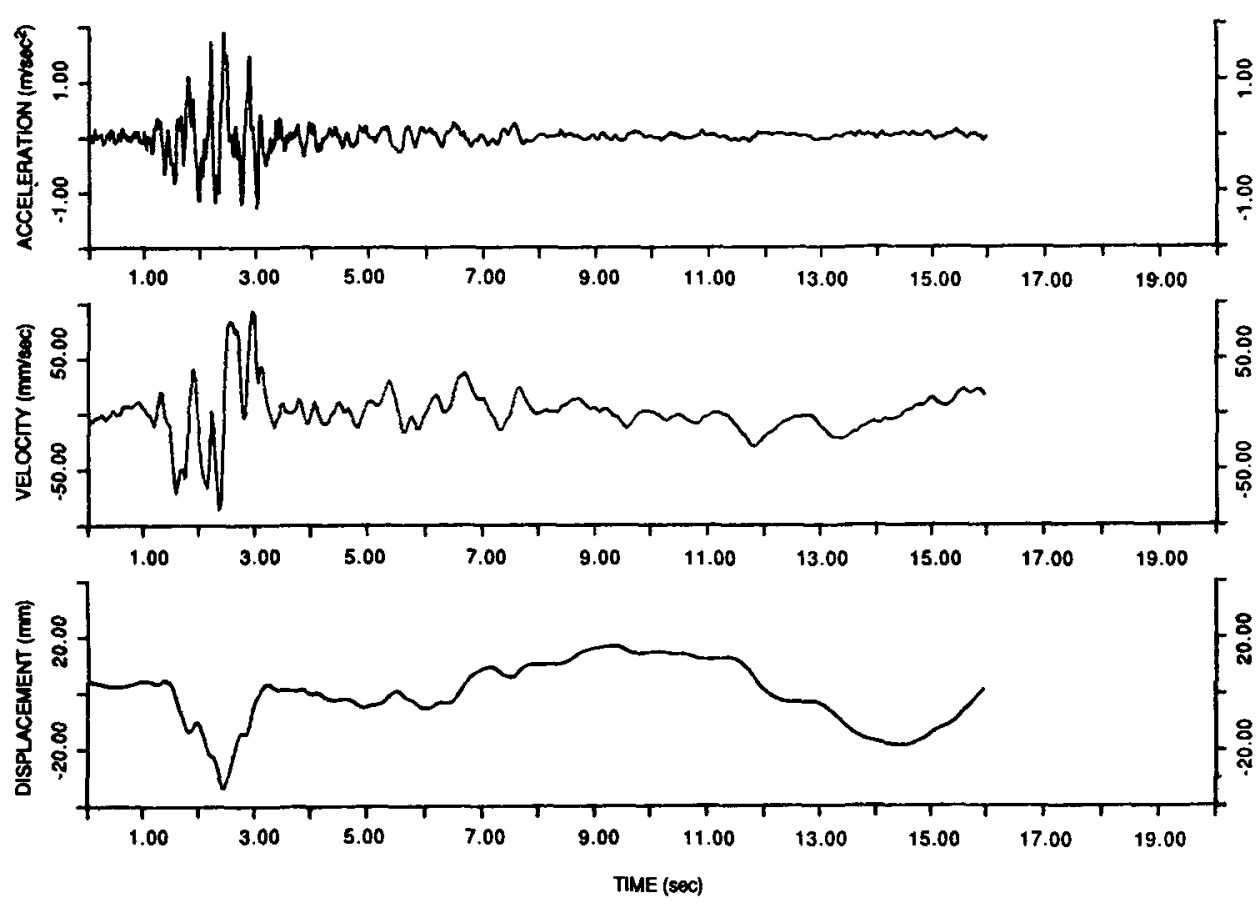

Figure 2. Recorded ground motions (N14E component) at the Dharamsala station in the Himachal Pradesh earthquake, April 26, 1986 (courtesy: A R Chandrasekaran). Epicentral distance about $5 \mathrm{~km}$.

publication of the set of these records with peak accelerations in excess of $0.2 \mathrm{~g}$ will be a valuable addition to the strong motion data base of India.

On August 20,1988, a major earthquake $\left(M_{S}=6.8\right)$ occurred in the Bihar-Nepal region, in approximately the same place as the devastating earthquake of January 15 , $1934\left(M_{S}=8.4\right)$. The recent earthquake had high intensity over a substantial area (Richter 1958), with 800 loss of life from collapsed structures reported. It underscores the need for adequate strong motion instrumentation along the whole Himalaya region (Arya et al 1986).

\section{Future developments}

The Department of Science and Technology of the Government of India has reported an integrated project in Himalayan seismicity, particularly in the Himachal and Garhwal areas in the Eastern Himalayas covering Assam and Meghalaya. As well, monitoring of seismic activity is carried out by the India Meteorological Department and by other organizations such as the Department of Earthquake Engineering in Roorkee and the National Geophysical Research Institute.

Construction of large dams in various River Valley Projects in India has led to additional seismic surveillance in various parts of the country (Srivastava and Dube 1982). The minimum seismographic networks needed for engineering projects of various sizes have been discussed (Srivastava 1987), both of sensitive instruments for 
local earthquake location (Agrawal 1978) and of strong motion type (Rau and Varma 1981). The policy of the Central Water Commission is to make seismic instrumentation an integral part of these developments and special requirements in the India construction code have been suggested.

The impounding of Shivaji Sagar Lake in 1962 by Koyna Dam led to much interest in reservoir-induced seismicity in India (Gupta, 1985). The continued occurrence of earthquakes in its vicinity (Rastogi and Talwani 1980) as well as the new major dams such as Navagam Dam in Gujarat provides ample justification for adequate future strong motion as well as sensitive seismic network around such facilities.

As mentioned in the introduction, the development of an enhanced all-India strong motion instrumentation network provides a singular opportunity to improve the basic knowledge of India earthquakes and to provide fundamental data for aseismic engineering design and seismic risk mitigation (Agbabian and Arya 1987). Continental-wide considerations and integration of both seismological and engineering needs (Bolt 1980) will help ensure that the observations of strong ground shaking are optimized and representative of various geological and soil conditions.

Because of the unique continent-continent collision tectonics of the Himalayan thrust, strong motion recordings in this region will also provide important information for fundamental studies of earthquake mechanisms, not only in India, but in similar geological conditions around the world. For example, recent research suggests that thrust type earthquakes produce higher accelerations than the normal and strike-slip earthquakes. This prediction depends on the friction-rupture relationships for faulting; other reasonable models might predict lower accelerations for thrust faults. Data from the unique conditions of the Himalayan thrust should provide important constraints on the parameters for modelling major earthquake ruptures.

Seismic gap theory should be given strong weight in consideration of the geographic strategy for deploying Indian strong motion arrays. It has now become clear from numerous successful predictions worldwide that seismic gaps usually represent regions of highest probability for very large earthquakes, although aftershock zones of earlier earthquakes often are the zones of highest short-term probability for smaller events. As the historic pattern of the occurrence of large events is now much better understood in relation to seismic gap theory (see other papers in this volume), it should play an important role in siting strategy.

It is hardly necessary to stress the need for a national plan aimed at standardizing the instrumentation and vital maintenance, developing rapid and validated recording, processing facilities, and establishing efficient data dissemination procedures. Valuable recommendations, objectives and resolutions relating to these questions are listed in the Proceedings of the 1987 Indo-U.S. Workshop on earthquake disaster mitigation research (Agbabian and Arya 1987).

Many decisions are required concerning the relative distribution of free-field instruments in relation to specific problems. Such instruments provide in time a sound physical basis for understanding the dynamics of faulting, the transmission of seismic waves through rocks and soils, possible nonlinear effects at soft-soil sites, topographic effects and the characteristic response of alluvial basins. Instrumentation of representative engineering structures such as buildings and dams is, of course, essential as well as installations to provide the seismic response of such "lifelines" as bridges and piping.

The major projects involving the Kangra and Shillong arrays are now providing 
experience in India with large regional arrays of the type classified as "source mechanism and were propagation arrays" at the 1978 International Workshop report (Iwan 1978). These Indian arrays are well situated to measure ground motions from great earthquakes that may occur from fault slip along two segments of the major boundary thrust fault system. Consideration of the priorities for arrays of different classification (Bolt et al 1987) such as liquefaction and soil-structural arrays is now opportune.

Objectives and guidelines for the deployment of strong ground motion arrays require appropriate indigenous studies but, in general, two criteria can be recommended:

(i) Arrays should be sited with specific aims to measure well-defined aspects of strong seismic motion, and

(ii) Siting should follow studies that optimize the scientific and engineering returns, given knowledge of the local three-dimensional geologic environment and the distribution of earthquake sources.

In the last few years, considerable experience has been obtained in a number of countries, particularly the United States (California), Japan and Taiwan, with digitally recording instruments. The older analog instruments were thought (e.g. Iwan 1978) to provide more reliable and tested data acquisition in various harsh field conditions. The modern digital accelerometers, however, have proven to be comparable in reliability and because of their extended dynamic range and simplicity of data processing (now with regular PC tape or disc input), they must be seriously considered. A decision in each case depends on answering the questions: What is the expected maintenance of each system? And how will limitations on operational life affect the overall recording objectives in the region?

Because large earthquakes may not occur for several years, there are special organizational and funding problems in maintaining long-range programmes for instrument maintenance, data analysis, archiving, distribution and data use. The only solution is stable, continuous commitment of government agencies and organizations with vigorous support from professional groups of seismologists and earthquake engineers. It is sometimes possible, as in the current California Strong Motion Instrumentation Programme (SMIP) to obtain significant financial support from mandatory small fees from large-scale building owners that are assessed at the time of building permit approval. (Currently this fee in California is 17 cents per 100 dollars construction cost, or $0.017 \%$ ).

It is crucial to pool strong motion data from every seismically active country of the world in a global effort to understand strong earthquake motions and mitigate seismic risk. An upgraded and integrated India strong motion network could contribute much to this international objective. The opportunity is particularly inviting following the recent creation of the Decade of Natural Disaster Reduction (19912000 ) by the United Nations. For a solution to the problems of earthquake hazard reduction, a key ingredient is more adequate sampling of strong seismic motions.

\section{Acknowledgements}

The authors would like to acknowledge the assistance of a number of colleagues in India, particularly Dr Jai Krishna at the University of Roorkee and Dr B K Rastogi at 
the National Geophysical Research Institute. Dr A R Chandrasekaran at the University of Roorkee generously supplied the strong motion records in figure 2. Dr D Hudson of the California Institute of Technology kindly provided comments.

\section{References}

Agbabian M S and Arya A S 1987 Earthquake disaster mitigation research. In Proc. Indo-US Workshop Jan. 19-23, 1987, N. Delhi 2

Agarwal P N 1978 Seismological instrumentation for local networks. In Symp. on Earthquake Eng. University of Roorkee, Vol. II, p. 10-13

Arya A S, Gupta S P, Lavania B V K and Kumar A 1986 Report on the Dharmsala, Himachal Pradesh earthquake, April 26, 1986, Dept. of Earthquake Engineering, University of Roorkee

Bapat A, Kulkarni R C and Guha S K 1983 Catalogue of earthquákes in India and neighbourhood (Roorkee: Indian Society of Earthquake Technology)

Bolt B A 1980 US earthquake observatories: recommendations for a new national network (Washington DC: Natl. Res. Council)

Bolt B A, Abrahamson N A, Darragh R B, Penzien J and.Tsai Y B 1987 The SMART 1 accelerograph array (1980-1987): A review; Earthquake Spectra 3 Univ. of S. Calif. 1987

Chandra U 1977 Earthquakes of Peninsula India: A seismotectonic study; Bull. Seismol. Soc. Am. 65 1387-1413

Chandrasekaran A R 1987 Measurement and analysis of strong earthquake ground motion; Bull. Indian Soc. Earthquake Tech. 24 77-86

Gupta H K 1985 The present status of reservoir induced seismicity investigations with special emphasis on Koyna earthquakes; Tectonophysics 118 257-279

Gupta H K, Rajendran K and Singh H N 1986 Seismicity of the northeast India region; J. Geol. Soc. India 343-406

Iwan W D 1978 Strong motion earthquake instrument arrays. In Proc. Int. Workshop on strong motion arrays, Calif. Inst. of Tech., Pasadena, USA Honolulu, Hawaii

Kaila K L and Sarkar D 1978 Atlas of isoseismal maps of major earthquakes in India; Geophys. Res. Bull. 16 234-267

Kaila K L and Rao N M 1979 Seismic zoning maps of the Indian subcontinent; Geophys. Res. Bull.,17 293-301

Khattri K N, Rogers A M and Perkins D M 1983 Estimates of seismic hazard in northeastern India and neighbourhood; Bull. ISET 20 1-22

Krishna J 1981 Geotechnical and strong motion aspects of recent Indian earthquakes. In Proc. Int. Conf. on Recent Advances in Geotechnical Earthquake Engineering and Soil Dynamics St. Louis pp. 845-848

Rao B R and Rao P S 1984 Historical seismicity of Peninsula India; Bull. Seismol. Soc. Am. 74 2519-2533

Rastogi B I and Talwani P 1980 Relocation of Koyna earthquakes; Bull. Seismol. Soc. Am. 70 1849-1868

Rau S N and Varma R K 1981 Planning instrumentation monitoring in dams. In Proc. Int. Conf. on Recent Advances in Geotechnical Earthquake Engineering and Soil Dynamics University of MissouriRolla pp. $855-856$

Richter C F 1958 Elementary seismology (San Francisco: W H Freeman)

Srivastava H N 1987 Seismological network in India for river valley projects; Bull. Indian Soc. Earthquake Tech. 24 67-76

Srivastava H N and Dube R K 1982 Seismicity studies of some important dams in India. In Proc. IV Int. Cong. Int. Assoc. Engl. Geol. India 7 219-227

Tandon A N and Choudhury H M 1968 Koyna earthquake of December 1967 India Meteorological Department Scientific Rept. No. 59 